\title{
Brown Adipose Tissue - role in metabolic disorders
}

\author{
Tahniyah Haq ${ }^{1}$, Frank Joseph Ong², Sarah Kanji ${ }^{3}$ \\ ${ }^{I}$ Department of Endocrinology, Bangabandhu Sheikh Mujib Medical University, Dhaka, Bangladesh; \\ ${ }^{2}$ Department of Pediatrics, McMaster University, Hamilton, Ontario, Canada; \\ ${ }^{3}$ Department of Medicine, University of Toronto, Toronto, Ontario, Canada
}

\begin{abstract}
Brown adipose tissue, a thermogenic organ, previously thought to be present in only small mammals and children has recently been identified in adult humans. Located primarily in the supraclavicular and cervical area, it produces heat by uncoupling oxidative phosphorylation due to the unique presence of uncoupling protein 1 by a process called nonshivering thermogenesis. BAT activity depends on many factors including age, sex, adiposity and outdoor temperature. Positron-emission tomography using ${ }^{18} \mathrm{~F}$-fluorodeoxyglucose and computed tomography $\left({ }^{18} \mathrm{~F}-\mathrm{FDG}\right.$ PET-CT), magnetic resonance imaging (MRI) and thermal imaging (IRT) are among several methods used to detect BAT in humans. The importance of BAT is due to its role in whole body energy expenditure and fuel metabolism. Thus it is postulated that it may be useful in the treatment of metabolic diseases. However, there are still many unanswered questions to the clinical usefulness of this novel tissue.
\end{abstract}

IMC J Med Sci 2019; 13(1): 002. EPub date: 03 February 2019

\section{Introduction}

The rediscovery of functional brown adipose tissue (BAT) in adult humans has generated interest in its potential as a therapeutic target to improve metabolic health. BAT is a thermogenic organ located primarily in the supraclavicular area in adult humans. Smaller deposits are also located in the paravertebral, perinephric and mediastinal areas [1-4]. They possess uncoupling protein 1 (UCP-1) which acts as an alternate proton channel through which hydrogen ions travel down the electrochemical gradient, bypassing adenosine triphosphate (ATP) synthase and dissipating energy as heat $[5,6]$. This process is called nonshivering thermogenesis and is activated by cold and regulated by the sympathetic nervous system $[6,7]$. Several studies have demonstrated that this thermometabolic organ contributes to whole body energy expenditure [8-11] and plays a role in glucose [11] as well as lipid metabolism [12]. There is ongoing research to explore the role of BAT in diseases such as type 2 diabetes mellitus, dyslipidaemia and nonalcoholic fatty liver disease. This review aims to highlight the morphology, location, mechanism of action, detection and clinical usefulness of BAT.

\section{Morphology}

BAT is richly vascularized and densely innervated by terminal fibres of the sympathetic nervous system. It is characterized by polygonal cells with a central nucleus and multiple, small vacuoles that store triglycerides (i.e. multilocular lipid droplets). They are characteristically rich in large, spherical UCP-1 containing mitochondria. UCP-1 is uniquely expressed in the inner mitochondrial membrane and is essential in the uncoupling of mitochondrial oxidative phosphorylation [5].

\section{Location and amount of BAT}

BAT is strategically located around major blood vessels to ensure adequate delivery of substrates and

Address for Correspondence:

Dr. Tahniyah Haq, Assistant Professor, Department of Endocrinology, Room 1620, 15th Floor, Block D, Bangabandhu Sheikh Mujib Medical University, Shahbag, Dhaka, Bangladesh. Tel phone: 01677791735, email tahniyah81@gmail.com 
effective dissipation of heat throughout the body [13]. Infants and children have a considerable amount of active BAT which gradually regresses with age, especially after puberty [14]. In infants, BAT consists of around $1-5 \%$ of their body weight [15] and is predominantly found in the interscapular region. Retrospective studies under non-cold stimulated conditions have found that ${ }^{18} \mathrm{~F}$ fluorodeoxyglucose $\left({ }^{18} \mathrm{~F}-\mathrm{FDG}\right)$ uptake is present in $6.8-8.5 \%$ of adults $[1,16,17]$. Out of these adults with detectable BAT activity, ${ }^{18} \mathrm{~F}$-FDG uptake is most commonly observed in the supraclavicular and cervical area (94.2\%), paravertebral area (61.6\%), mediastinal/para-aortic (28\%) and perirenal areas (20.1\%) [17]. Histological examination of tissue from the supraclavicular region has confirmed the presence of BAT $[1-4,8,16,17]$. The estimated amount of active BAT found in adult humans ranges from 4 to more than $1500 \mathrm{ml}$ [18].

\section{Mechanism of nonshivering thermogenesis}

As noted earlier, BAT is characterized by an abundance of UCP-1 containing mitochondria.

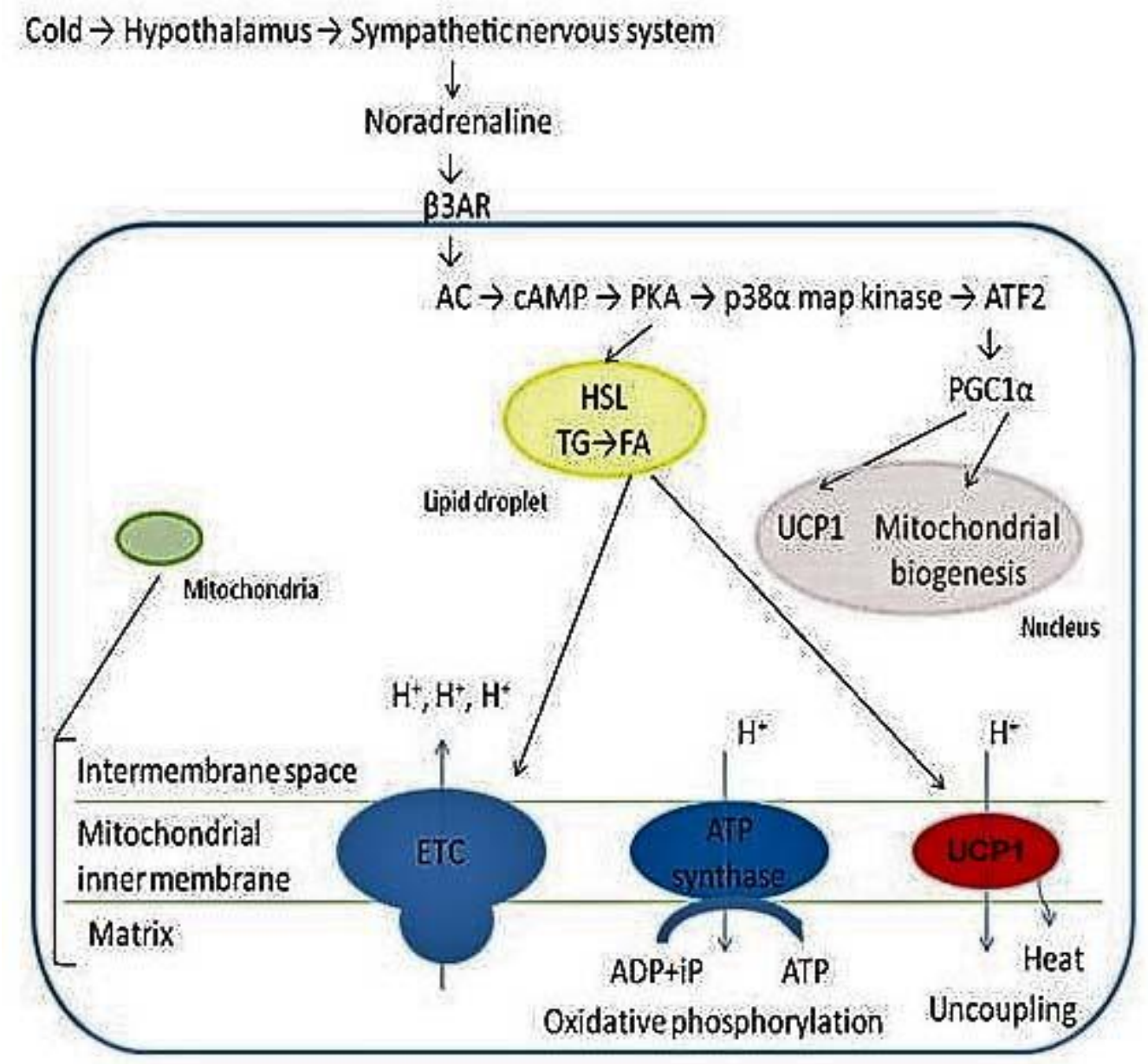

Fig-1. Nonshivering thermogenesis in brown adipocyte. Cold activates BAT via release of noradrenaline which binds with the $\beta 3$ receptor on the cell surface. This activates a downstream cascade of events in which PPAR coactivator $1 \alpha(P G C 1 \alpha)$ is a key regulator of thermogenesis due to its ability to induce expression of UCP-1 [6]. B3AR: $\beta 3$ adrenoreceptor, AC: adenylate cyclase, cAMP: cyclic adenosine monophosphate, PKA: protein kinase A,

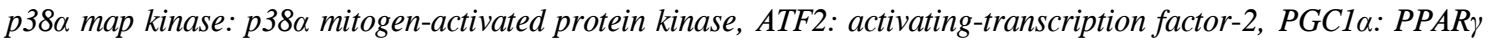
coactivator 1a, UCP-1: uncoupling protein 1, HSL: hormone sensitive lipase, TG: triglyceride, FA: fatty acid, ETC: electron transport chain. 
UCP-1, a six-domain transmembrane protein, is central to the production of heat by nonshivering thermogenesis. The expression of UCP-1 can be enhanced by adrenergic stimulation and peroxisome proliferator-activated receptor- $\gamma$ (PPAR $\gamma)$ agonists [6]. Factors that can increase the metabolic activity of BAT include the use of sympathomimetics, $\beta$ adrenergic agonists and cold exposure [6,7,1921,25]. During BAT activation, there is upregulation of UCP-1, which allows protons to travel down the electrochemical gradient while bypassing the ATP synthase. As a result of this uncoupling of oxidative phosphorylation, ATP is not synthesized and energy is dissipated as heat. With less ATP production, there is no negative feedback inhibition of the respiratory chain, producing a futile cycle [6] (Figure 1).

\section{Factors associated with BAT activity in humans}

In addition to the cooling protocol, the prevalence of BAT also depends on age, sex, adiposity and outdoor temperature [17]. Age is an independent negative predictor of BAT activity and mass, with BAT being more prevalent in younger individuals $[2,10,16,17,22,23]$. However, the cause of this age-dependent decline in BAT is currently unknown, but changes in sex and thyroid hormones as well as the activity of the sympathetic nervous system associated with increasing age have been speculated to be contributing factors [24]. Females have been observed to have more BAT activity and mass compared to males in some studies $[16,17,22]$ but not all studies $[23,25,26]$. The difference in the prevalence of BAT between males and females may be due to the different effects of sex hormones on BAT activity [22] and the fact that females start to shiver at a higher temperature compared to males [27]. Body mass index (BMI), central obesity, body fat percentage and visceral fat are consistently lower in people with detectable BAT activity $[2,10,16,23,28,29]$. BMI is not only negatively correlated with BAT, but is also an independent predictor $[1,2,16-17,28]$. Whether increased BAT activity results in a lower BMI or vice versa is still not known. Nahon and colleagues reported that larger individuals with higher lean mass require exposure to lower temperatures to activate cold-induced thermogenesis due to higher basal heat generation in this population. As such, studies investigating the relationship between BAT and adiposity should consider body size, composition and energy expenditure when designing coldinduced thermogenesis studies [30]. BAT is more likely to be detected during the winter compared to summer [1,2,31]. In addition, BAT activity and mass is inversely related with outdoor temperature at the time [1] or day [17,32] of the scan. These studies show that lower outdoor temperature is associated with increased BAT prevalence, volume and activity.

\section{Methods of BAT detection}

Multiple imaging modalities have been utilized to characterize and differentiate BAT from surrounding tissues based on its unique anatomical and functional properties. These techniques include ${ }^{18}$ F-FDG PET-CT, magnetic resonance imaging (MRI), infrared thermography (IRT) and autonomous temperature sensors (i.e. iButtons). A detailed review outlining recent advances in BAT detection has recently been published by our group and therefore will only be briefly discussed [33]. ${ }^{18} \mathrm{~F}$ FDG PET-CT is the current reference standard in the detection of BAT. This modality measures the uptake of a glucose analogue (i.e. ${ }^{18} \mathrm{~F}-\mathrm{FDG}$ ) that is taken up by BAT but is not metabolized [34] Moreover, PET-CT has been instrumental in advancing our knowledge in the identification, location and nature of BAT [1-3,8,16,17]. However, a major limitation of PET-CT is the significant and unnecessary exposure to ionizing radiation precluding its use in large cohorts and in children [35]. Thus, alternative modalities including MRI have been utilized in the detection of BAT. The use of this technique is dependent on the morphological differences between BAT and surrounding tissues resulting in unique $\mathrm{MR}$ signatures which can be measured using fatfraction $(\mathrm{FF})$ and $\mathrm{T} 2 *$ relaxation $(\mathrm{T} 2 *)$. Generally, BAT is characterized by smaller FF and $\mathrm{T} 2 *$ values due to its lower lipid content, greater vascularization and abundance of iron-rich mitochondria. In addition, both $\mathrm{FF}$ and $\mathrm{T} 2 *$ can also be used to measure BAT metabolic activity as reductions in these parameters have been associated with ${ }^{18}$ F-FDG uptake [36]. Imaging modalities that measure changes in skin temperature including IRT and autonomous 
temperature sensors have been used to detect BAT [13]. These techniques rely on the heat produced by BAT via non-shivering thermogenesis in the overlying skin when activated. However, the use of these modalities in measuring BAT activity is often confounded by skin thickness, increased blood flow and muscle activity upon cold exposure. As such, further investigation is warranted before these modalities can be widely adapted in the measurement of BAT. Other emerging modalities are currently being developed to measure BAT. However, these methods are of limited availability, expensive and still in their infancy. Examples include detection of BAT using hyperpolarized MRI [37,38], contrast ultrasound, near-infrared fluorescence imaging [39] and nearinfrared time-resolved spectroscopy.

\section{Therapeutic potential}

As alluded above, BAT presence and activity is negatively associated with weight and central adiposity, suggesting a possible role of this tissue in the context of obesity [8-11,29]. In addition, when BAT is activated, it uses endogenous derived fatty acids, free fatty acids [12,41] and glucose [11] as its fuel source, suggesting that this thermometabolic organ contributes to wholebody energy homeostasis. A study by Iwen and colleagues demonstrated that cold-induced BAT activation resulted in increased peripheral glucose uptake and higher insulin sensitivity without influencing pancreatic hormone secretions [41]. As such, it is not surprising that fasting blood glucose is lower in those with BAT than those without; and BAT activity is inversely correlated with fasting glucose concentration [16,41-43]. Chronic cold exposure induces weight loss [44] and increases insulin sensitivity by activating BAT in humans $[45,46]$. Recent studies showing metabolic improvement independent of thermogenesis after BAT transplantation in mice postulate that BAT is an endocrine organ, secreting cytokines such as IL-6 and FGF21 which have beneficial effects on other organs of the body [47,48]. Therefore, BAT shows potential in the treatment of not only obesity, but also diabetes mellitus, dyslipidaemia and nonalcoholic fatty liver disease and thus warrants further investigation.

\section{Conclusion}

There has been considerable research over the last few decades demonstrating the morphology, mechanism and presence of BAT in adult humans. Although there is ongoing work regarding the measurement of this novel tissue in humans, many challenges still need to be overcome. Furthermore, studies need to be designed to determine ways to stimulate and recruit BAT as well as to determine how effective and clinically relevant BAT thermogenesis will be in the treatment of metabolic disorders.

\section{Acknowledgments}

We acknowledge Dr. Gregory R Steinberg, Department of Biochemistry and Biomedical Sciences, McMaster University and Dr. Katherine M Morrison, Department of Pediatrics, McMaster University for their advice and suggestions in writing the review.

\section{Author's contributions}

TH, FJO and SK wrote and edited the manuscript.

\section{Competing interest}

There is no conflict of interest.

\section{References}

1. Cypess AM, Lehman S, Williams G, Tal I, Rodman D, Goldfine AB, et al. Identification and importance of brown adipose tissue in adult humans. $N$ Engl J Med. 2009; 360: 1509-1517.

2. Saito M, Okmatsu-Ogura Y, Matsushita M, Watanabe K, Yoneshiro T, Nio-Kobayashi J, et al. High incidence of metabolically active brown adipose tissue in healthy adult humans: effects of cold exposure and adiposity. Diabetes. 2009; 58: 1526-1531.

3. Virtanen KA, Lidell ME, Orava J, Heglind M, Westergren R, Niemi $\mathrm{T}$, et al. Functional brown adipose tissue in healthy adults. $N$ Engl J Med. 2009; 360: 1518-1525.

4. Zingaretti MO, Crosta F, Vitali A, Guerrieri M, Frontini A, Cannon B, et al. The presence 
of UCP-1 demonstrates that metabolically active adipose tissue in the neck of adult humans truly represents brown adipose tissue. FASEB Journal. 2009; 23: 3113-3120.

5. Cinti S. Reversible physiological transdifferentiation in the adipose organ. Proceedings of the Nutrition Society. 2009; 68: 340-349.

6. Richard D, Carpentier AC, Dore' G, Ouellet V, Picard F. Determinants of brown adipocyte development and thermogenesis. Int $J$ Obes. 2010; 34: S59-S66.

7. Cannon B, Nedergaard J. Brown adipose tissue: function and physiological significance. Physiol. Rev. 2004; 84: 277-359.

8. Van Marken Lichtenbelt WD, Vanhommerig JW, Smulders NM, Drossaerts J M, Kemerink GJ, Bouvy ND, et al. Cold activated brown adipose tissue in healthy men. $N$ Engl J Med. 2009; 360: 1500-1508.

9. Orava J, Nuutila P, Lidell ME, Oikonen V, Noponen $\mathrm{T}$, Viljanen $\mathrm{T}$, et al. Different metabolic responses of human brown adipose tissue to activation by cold and insulin. Cell Metab. 2011; 14: 272-279.

10. Yoneshiro T, Aita S, Matsushita M, Kameya T, Nakada K, Kawai Y, et al. Brown Adipose Tissue, Whole-Body Energy Expenditure, and Thermogenesis in Healthy Adult Men. Obesity. 2011; 19: 13-16.

11. Ouellet V, Labbe SM, Blondin DP, Phoenix $\mathrm{S}$, Guerin B, Haman F, et al. Brown adipose tissue oxidative metabolism contributes to energy expenditure during acute cold exposure in humans. J Clin Invest. 2012; 122: 545-552.

12. Bartelt A, Bruns OT, Reimer R, et al. Brown adipose tissue activity controls triglyceride clearance. Nat Med. 2011; 17: 200-205.

13. Boon MR, Bakker LE, Van der Linden RA, Arias-Bouda LP, Smit F, Verberne HJ, et al. Supraclavicular skin temperature as a measure of 18F-FDG uptake by BAT in human subjects. PLoS ONE. 2014; 9(6): e98822. doi: 10.1371/journal.pone.0098822.

14. Virtanen KA, Nuutila P. Brown adipose tissue in humans. Nutr Metab. 2011; 22: 49-54.
15. Hull D. The function of brown adipose tissue in the newborn. Biochem Soc. Trans. 1976; 4: 226-228.

16. Lee P, Greenfield JR, Ho KKY, Fulham MJ A critical appraisal of the prevalence and metabolic significance of brown adipose tissue in adult humans. Am J Physiol Endocrinol Metab. 2010; 299(4): E601-E606.

17. Ouellet V, Routhier-Labadie A, Bellemare W, Lakhal-Chaieb L, Turcotte E, Carpentier AC, et al. Outdoor Temperature, Age, Sex, Body Mass Index, and Diabetic Status Determine the Prevalence, Mass, and Glucose-Uptake Activity of 18. F-FDG-Detected BAT in Humans. $J$ Clin Endocrinol Metab. 2011; 96: 192-199.

18. Blondin DP, Labbé SM, Turcotte EE, Haman F, Richard D, Carpentier AC. A critical appraisal of brown adipose tissue metabolism in humans. Clin Lipidol. 2015; 10: 259-280.

19. Carey AL, Formosa MF, Van Every B, Bertovic D, Eikelis N, Lambert GW. Ephedrine activates brown adipose tissue in lean but not obese humans. Diabetologia. 2013; 56: 147-155.

20. Vosselman MJ, Van Der Lans AAJJ, Brans B, Wierts R, Van Baak MA, Schrauwen P. Systemic b-adrenergic stimulation of thermogenesis is not accompanied by brown adipose tissue activity in humans. Diabetes. 2012; 61: 3106-3113.

21. Cypess AM, Weiner LS, Roberts-Toler C, Elía EF, Kessler SH, Kahn PA. Activation of human brown adipose tissue by a $\beta 3$ adrenergic receptor agonist. Cell Metab. 2015; 21: 33-38.

22. Pfannenberg C, Werner MK, Ripkens S, Stef I, Deckert A, Schmadl M, et al. Impact of age on the relationships of brown adipose tissue with sex and adiposity in humans. Diabetes. 2010; 59: 1789-1793.

23. Brendle C, Werner MK, Schmadl M, Ia Fourgere C, Nikolaou K, Stegan $\mathrm{N}$, et al. Correlation of brown adipose tissue with other body fat compartments and patient characteristics: A retrospective analysis in a large patient cohort using PET/CT. Acad Radiol. 2018; 25(1): 102-110. 
24. Lecoultre V, Ravussin E. Brown adipose tissue and aging. Cur Opin Clin Nutr Metab Care. 2011; 14: 1-6.

25. Cypess AM, Chen YC, Sze C, Wang K, English J, Chan O, et al. Cold but not sympathomimetics activates human brown adipose tissue in vivo. Proc Natl Acad Sci USA. 2012; 109(25): 10001-10005.

26. Van der Lans AAJJ, Hoeks J, Brans B, Vijgen GHEJ, Visser MGW, Vosselman MJ, et al. Cold acclimation recruits human brown fat and increases nonshivering thermogenesis. $J$ Clin Inv. 2013; 123(8): 3395-3403.

27. Van der Lans AAJJ, Wierts R, Vosselman MJ, Schrauwen P, Brans B, van Marken Lichtenbelt WD. Cold-activated brown adipose tissue in human adults: methodological issues. Am J Physiol Regul Integr Comp Physiol. 2014; 307: R103-R113.

28. van Marken Lichtenbelt WD, Schrauwen P. Implications of nonshivering thermogenesis for energy balance regulation in humans. $\mathrm{Am} J$ Physiol Regul Integr Comp Physiol. 2011; 301: R285-R296.

29. Green AL, Bagci U, Hussein S, Kelly PV, Muzaffar R, Neuschwander-Tetri BA, et al. Brown adipose tissue detected by PET/CT imaging is associated with less central obesity. Nucl Med Commun. 2017; 38(7): 629-635.

30. Nahon KJ, Boon MR, Doornink F, Jazet IM, Rensen PCN, Abreu-Vireira G. Lower critical temperature and cold-induced thermogenesis of lean and overweight humans are inversely related tobody mass and basal metabolic rate. J Therm Biol. 2017; 69: 238-248.

31. Cohade C, Mourtzikos KA, Wahl RL. 'USAFat'": Prevalence Is Related to Ambient Outdoor Temperature--Evaluation with $18 \mathrm{~F}$ FDG PET/CT. The Journal of Nuclear Medicine. 2003; 44: 1267-1270.

32. Huang YC, Hsu CC, Wang PW, Chang Yh, Chen TB, Lee BF, et al. Review Analysis of the Association between the Prevalence of Activated Brown Adipose Tissue and Outdoor Temperature. The Scientific World Journal. 2012; 2012: 793039.
33. Ong FJ, Ahmed BA, Oreskovich SM, Blondin DP, Haq T, Konyer NB, et al. Recent advances in the detection of brown adipose tissue in adult humans: a review. Clinical Science. 2018; 132(10): 1039-54.

34. Nedergaard J, Bengtsson T, Cannon B Unexpected evidence for active brown adipose tissue in adult humans. Am J Physiol Endocrinol Metab. 2007; 293(2): E444-52.

35. Cypess AM, Haft CR, Laughlin MR, Hu HH. Brown fat in humans: Consensus points and experimental guidelines. Cell Metab. 2014; 20: $408-415$.

36. Chen Y I, Cypess A M, Chen Y, Palmer M, Kolodny G, Kahn C R, et al. Measurement of Human Brown Adipose Tissue Volume and Activity Using Anatomic MR Imaging and Functional MR Imaging. J Nucl Med. 2013; 54: 1584-1587.

37. Branca RT, White C, Zhang L. Detection of brown fat mass and activity by hyperpolarized xenon MR. Proceedings of the 21st Annual Meeting ISMRM, Salt Lake City, UT. 2013; 404.

38. Lau AZ, Chen AP, Gu Y, Ladouceur-Wodzak $\mathrm{M}$, Nayak KS, Cunningham $\mathrm{CH}$. Noninvasive identification and assessment of functional brown adipose tissue in rodents using hyperpolarized $13 \mathrm{C}$ imaging. Int. J. Obes. (Lond.). 2014; 38: 126-131.

39. Azhdarinia A, Daquinag AC, Tseng C, Ghosh SC, Ghosh P, Amaya-Manzanares F, et al. A peptide probe for targeted brown adipose tissue imaging. Nat. Coтmu. 2013; 4: 2472.

40. Nirengi S, Takeshi Yoneshiro T, Hiroki Sugie H, Masayuki Saito M, and Takafumi Hamaoka T. Human Brown Adipose Tissue Assessed by Simple, Noninvasive Near-Infrared TimeResolved Spectroscopy. Obesity. 2015; 23: 973-980.

41. Iwen KA, Backhaus J, Cassens M, Walti M, Hedesan OC, Merkel M, et al. Cold-induced brown adipose tissue activity alters plasma fatty acids and improves glucose metabolism in men. $J$ Clin Endocrinol Metab. 2017; 102(11): 4226-4234. 
42. Jacene HA, Wahl RL. The Importance of Brown Adipose Tissue. $N$ Engl J Med. 2009; 361(4): 417-418.

43. Stefan N, Pfannenberg C, Häring HU. The Importance of Brown Adipose Tissue. $N$ Engl J Med. 2009; 361(4): 416-417.

44. Yoneshiro T, Aita S, Matsushita M, et al. Recruited brown adipose tissue as an antiobesity agent in humans. J Clin Invest. 2013; 123: 3404-3408.

45. Lee $\mathrm{P}$, Smith $\mathrm{S}$, Linderman $\mathrm{J}$, et al. Temperature-acclimated brown adipose tissue modulates insulin sensitivity in humans. Diabetes. 2014; 63: 3686-369.
46. Hanssen MJW, Hoeks J, Brans B, van der Lans AAJJ, Schaart G, van den Driessche JJ, et al. Short-term cold acclimation improves insulin sensitivity in patients with type 2 diabetes mellitus. Nat Med. 2015; 21(8): 863865.

47. Liu X, Wang S, You Y, Meng M, Zheng Z, Dong $\mathrm{M}$, et al. Brown adipose tissue transplantation reverses obesity in ob/ob mice. Endocrinology. 2015; 156: 2461-2469.

48. Poekes L, Lanthier N, Leclercq IA. Brown adipose tissue: a potential target in the fight against obesity and the metabolic syndrome. Clin Sci. 2015; 129: 933-949. 